\title{
Multi-Objective Optimal Dispatch Solution of Solar-Wind-Thermal System Using Improved Stochastic Fractal Search Algorithm
}

\author{
Tushar Tyagi, Hari Mohan Dubey*, Manjaree Pandit \\ Department of Electrical Engineering, M.I.T.S., Gwalior, India \\ E-mail: tshrtyg@gmail.com,harimohandubey@rediffmail.com and manjaree_p@hotmail.com \\ *Corresponding Author: Hari Mohan Dubey; Department of Electrical Engineering, M.I.T.S., Gwalior, India, Tel: +91 - \\ 0751-2409348, Fax: +90 312123 4567, harimohandubey@ rediffmail.com
}

\begin{abstract}
This paper presents solution of multi-objective optimal dispatch (MOOD) problem of solar-wind-thermal system by improved stochastic fractal search (ISFSA) algorithm. Stochastic fractal search (SFSA) is inspired by the phenomenon of natural growth called fractal. It utilizes the concept of creating fractals for conducting a search through the problem domain with the help of two main operations diffusion and updating. To improve the exploration and exploitation capability of SFSA, scale factor is used in place of random operator. The SFSA and proposed ISFSA is implemented and tested on six different multi objective complex test systems of power system. TOPSIS is used here as a decision making tool to find the best compromise solution between the two conflicting objectives. The outcomes of simulation results are also compared with recent reported methods to confirm the superiority and validation of proposed approach.
\end{abstract}

Index Terms-Meta-heuristic, MOOD, TOPSIS, Fractals, Renewable energy.

\section{INTRODUCTION}

Economic load dispatch (ELD) is an important issue related to power system operation and control with goal is to reduce the total operating cost of electricity generation while satisfying all complex practical operating constraints. With the increase of environment awareness, pollution contributed by the thermal power plants, the ELD cannot fulfill the sustainability of the environment because of high amount of emitted pollutants. A possible solution of this problem is to switch to the low emission fuels but this is economical in long term due to its high price and low availability. On the other hand, economic emission dispatch (EED) recently becoming more popular. In EED both cost and emission minimized together for the optimal operation of the thermal power plant and sustainability of the environment without switching to low emission fuels.

EED is a complicated multi-objective constrained optimization problem with two competing objectives as cost and emission. These problems are solved by converting the problem as single objective problem using weighted sum approach. Different weights are assigned to fuel cost and emission to get an optimal Pareto front, which helps to find out the best compromise solution (BCS).

Earlier EED was solved by goal programming method [1] or weighted min-max method [2]. But in the last decade various nature inspired algorithm were developed to solve the EED problem like Differential Evolution (DE) [3], simulated annealing (SA) algorithm [4], Bacterial foraging algorithm (BFA) [5]- [6] Teaching learning based optimization (TLBO) [7], gravitational search algorithm(GSA) [8], Real coded Chemical Reaction algorithm(RCCRO) [9], Backtracking search algorithm (BSA) [10] and etc. Also algorithm likeCuckoo Search Algorithm (CSA) [25],Cat Swarm Optimization (CSO)[26] and Ant Colony Optimization(ACO) [27] are used for optimization of real world problem.

Demand of electricity is increasing day by day and hence utilization of renewable energy resources such as wind and solar power has been increasing over the past decade to reduce the energy crisis as well as to reduce environmental pollution especially global warming. However large scale integration of wind and solar power into existing power grid creates new operational challenges in the resulting ELD problem. The main problem associated with photo-voltaic (PV) system is weather controlled power generation and very high initial capital cost as compared to the same size of a diesel generator but the operating cost is very low and also the pollution is zero for the PV system. On the other hand, unpredictable nature of wind power creates more complication in ELD model. Hence reformulation of classical ELD model [11] is required considering issues as probabilistic based modeling of wind power, Impact of solar and wind power on emission emitted by thermal power plant. Also complex model of combined solarwind-thermal system requires efficient algorithm. The wind integrated ED modeling can be presented in [12-14]. Modeling of hybrid solar-wind system is presented in [15] whereas modeling of integrated solar-wind-thermal system is presented in [16]. A comprehensive review of hybrid renewable energy system by evolutionary algorithms is presented in [17]. 
In this paper a novel optimization algorithm namely Improved Stochastic Fractal Search Algorithm (ISFSA) is used to solve the MOOD problems with and withoutrenewable power integration. ISFSA utilizes scale factor in place of random operator in Stochastic Fractal Search Algorithm (SFSA) [18] to enhance exploration and exploitation capability during optimization.

This paper is organized as: Problem formulation for MOOD problem, modeling of PV system and modeling of wind farm are presented in section 2. The idea behind SFSA and its improvisation is presented in section 3 and section 4. TOPSIS for selection of best compromise solution is presented in section 5. The implementation process of ISFSA for solution of MOOD problem are depicted in section 6 , whereas section 7 presents result and discussion of simulation results. Finally concluding remarks is presented in section 8 .

\section{Multi OBJective Optimal Dispatch}

The objective for a solar-wind-thermal system is the simultaneous minimization of total operating cost and emitted emission.

\section{A. Minimization of Cost:}

As the solar power plant has no operating cost, Total operating cost $\left(F_{t}\right)$ consist thermal cost and the cost associated with wind power depicted as:

$$
\min F_{t}=\sum_{i=1}^{m} F_{t h}\left(P_{i}\right)+\sum_{j=1}^{n} F_{w}\left(P_{\text {wind }}^{j}\right)
$$

$F_{t h}\left(P_{i}\right)$ is thermal cost and $F_{w}\left(P_{\text {wind }}^{j}\right)$ is the cost associated with wind power generation. The cost associated with thermal power generation can be represented as:

$$
F_{t h}\left(P_{i}\right)=\left(a_{i} P_{i}^{2}+b_{i} P_{i}+c_{i}\right)(\$ / \mathrm{hr} .)
$$

Where $a_{i}, b_{i}$, and $c_{i}$ are the fuel cost coefficients of $i^{\text {th }}$ thermal unit.

Considering valve point loading (VPL) effect thermal power generation cost depicted as:

$$
F_{t h}\left(P_{i}\right)=a_{i} P_{i}^{2}+b_{i} P_{i}+c_{i}+\left|d_{i} \sin \left(e_{i}\left(P_{i}^{\min }-P_{i}\right)\right)\right|(\$ / \mathrm{hr} .)
$$

Where, $d_{i}$ and $e_{i}$ are fuel cost coefficients corresponding to VPL effect; $m$ is the number of thermal units.

The cost associated with wind power output using wind power coefficient $K_{j}$ as given hereunder [12]

$$
F_{w}\left(P_{\text {wind }}^{j}\right)=\sum_{j=1}^{n} K_{j} \times P_{\text {wind }}^{j}
$$

$n$ is the number of wind farm.

\section{B. Minimization of Emission:}

Here objective is to minimize emission depicted as:

$$
\begin{gathered}
\min E_{t}=\sum_{i=1}^{m} E_{t h}\left(P_{i}\right) \\
E_{t h}\left(P_{i}\right)=\left(\alpha_{i} P_{i}^{2}+\beta_{i} P_{i}+\gamma_{i}\right) \\
E_{t h}\left(P_{i}\right)=\left(\alpha_{i} P_{i}^{2}+\beta_{i} P_{i}+\gamma_{i}\right)+\zeta_{i} \exp \left(\lambda_{i} P_{i}\right)
\end{gathered}
$$

$E_{t h}$ is the total amount of emission in ton $/ \mathrm{hr}$, and $\alpha_{i}, \beta_{i}, \lambda_{i}, \zeta_{i}, \lambda_{i}$ are the emission coefficients of $i^{t h}$ generator.

\section{Problem formulation of $M O O D$}

Here bi-objective problem is converted into a single objective one using weighted sum approach as [22]:

$$
F_{\text {TотAL }}=w \times F_{t}+(1-w) \times E_{t} ; w \in(0,1)
$$

Subjected to following constraints

\section{Equality constraints}

$$
P_{D}+P_{L}=\sum_{i=1}^{m} P_{i}+P_{P V}+\sum_{j=1}^{n} P_{\text {wind }}^{j}
$$

$\mathrm{P}_{\mathrm{D}}$ represents the system power demand (MW), $\mathrm{P}_{\mathrm{L}}$ is the total transmission loss of the system (MW). $\mathrm{P}_{\mathrm{L}}$ is obtained using B-matrix coefficient as [11]:

$$
P_{L}=\sum_{i=1}^{m} \sum_{j=1}^{m} P_{i} \mathrm{~B}_{\mathrm{ij}} \mathrm{P}_{\mathrm{j}}+\sum_{i=1}^{m} B_{o i} \mathrm{P}_{\mathrm{i}}+\mathrm{B}_{\mathrm{oo}}
$$

\section{E. Inequality constraints}

Generation power should lie within minimum and maximum values.

$$
P_{i}^{\min } \leq P_{i} \leq P_{i}^{\max }
$$

$P_{i}^{\min }$ and $P_{i}^{\max }$ is the minimum and maximum generation capacity for $i^{\text {th }}$ thermal units.

\section{II -A. Modeling of Photo-Voltaic System}

Power output of photo-voltaic (PV) system is represented as [20]:

$$
P_{P V}=\eta A \lambda
$$

Where $P_{P V}$ is the power output in $\mathrm{MW} / \mathrm{h}, A$ is the total area of the photo-voltaic cell in $\mathrm{m}^{2}, \lambda\left(\mathrm{KWh} / \mathrm{m}^{2}\right)$ is the total radiation incident on PV system and $\eta$ is the system efficiency.

$$
\eta=\eta_{1} \eta_{2} P_{f}
$$

Where, $\eta_{1}$ is the module efficiency, $\eta_{2}$ is the power conditioning efficiency and $P_{f}$ is the packing factor.

$$
\eta_{1}=\eta_{r}\left[1-\beta\left(T_{c}-T_{r e f}\right)\right]
$$

Where, $\eta_{r}$ is the module reference efficiency, $\beta$ is 
array efficiency temperature coefficient, $T_{c}$ is the monthly average cell temperature and $T_{\text {ref }}$ is the reference temperature. The radiation and temperature data are adopted from [21], and also presented in Appendix A.

\section{II-B. MODELING OF WIND FARM}

Exact wind speed and power forecast majorly affects wind farm ideal dispatch. The wind velocity is an arbitrary variable and wind power imparts a nonlinear connection to it. The wind speed information from different places is found to take after Weibull distribution nearly and it is use for processing wind speed and wind power.

Probability density function of wind velocity is expressed as [12]:

$$
p d f(u)=\frac{\beta}{\alpha}\left(\frac{u}{\alpha}\right)^{\beta-1} \exp \left[-\left(\frac{u}{\alpha}\right)^{\beta}\right]
$$

Hera $\alpha$ and $\beta$ are shape and scale factor respectively. The wind power $\left(W_{p}\right)$ can be represented as a stochastic variable and calculated from wind speed as [12].

$$
P_{\text {wind }}^{j}=\left\{\begin{array}{lr}
0 & \left(u<u_{c i} \text { or } u \geq u_{c o}\right) \\
P_{\text {wind }}^{j R} & \left(u_{r} \leq u<u_{c o}\right) \\
\frac{\left(u-u_{\text {in }}\right) P_{\text {wind }}^{j R}}{u_{r}-u_{\text {in }}} & \left(u_{c i} \leq u<u_{r}\right)
\end{array}\right.
$$

Here $u_{r}, u_{c i}$ and $u_{c o}$ are rated wind speed, cut-in speed and cut-out speed respectively. $P_{\text {wind }}^{j}$ is the wind power output of $\mathrm{j}^{\text {th }}$ wind unit. It is quite clear from (16) that when wind speed is either less than the cut-in speed or greater than the cut-out speed the wind power output is zero. The power output of the wind unit is a continuous variable when the wind speed is between the rated and cut-in speed and the pdf is given as per the (15) The total of all wind generator yields is taken as one random variable $P_{\text {wind }}^{j}$ and the pdf is given by

$$
\begin{gathered}
p d f\left(P_{\text {wind }}\right)= \\
\frac{\beta \gamma u_{\text {in }}}{P_{\text {wind }}^{j R} \alpha}\left[\frac{\left(1+\frac{\gamma P_{\text {wind }}^{j}}{P_{\text {wind }}^{j R}}\right) u_{\text {in }}}{\alpha}\right]^{\beta-1} \cdot \exp \left[-\left\{\frac{\left(1+\frac{\gamma P_{\text {wind }}^{j}}{P_{\text {wind }}^{j R}} v_{\text {in }}\right.}{\alpha}\right\}\right.
\end{gathered}
$$

$$
\text { Here } \gamma=\left(\left(\frac{u_{r}}{u_{c i}}\right)-1\right) \text {. }
$$

To describe the condition that the available power is not ample to satisfy the total demand with losses, a probabilistic tolerance $\delta_{a}$ is chosen to model the uncertainty of wind power availability. In context to this the power balance constraint in (9) with wind and solar power is modified as expressed below.

$$
P_{r}\left(\sum_{j=1}^{n} P_{\text {wind }}^{j}+\sum_{i=1}^{m} P_{i}+P_{P V} \leq\left(P_{D}+P \text { Loss }\right) \leq \delta_{a}\right.
$$

A smaller value of $\delta_{a}$ decreases the risk of not enough wind power and increases the thermal generation to ensure the good reserve capacity.

\section{StOcAstic Fractal SEARCH AlgORITHM (SFSA)}

Stochastic fractal search is a bio inspired algorithm developed by Hamid Salimi in 2015 [18]. It is a metaheuristic type algorithm which imitates the phenomenon of natural growth. It used the mathematical tool of fractal to imitate the growth. A fractal is a repeated graphical pattern which can be observed on many natural objects like leaves of trees, wings of peacock or patterns created in the sky due to electrical discharge. The SFSA utilizes the concept of creating fractals for conducting a search through the problem domain. The random fractals are generated by using any mathematical method like Levy flight, Gaussian walks, percolation clusters or Brownian motion. The main operations performed are diffusion and updating.

In SFSA diffusion is carried out using Gaussian distribution. Each solution diffuses around its current position and generates similar solutions until a cluster is formed, promoting exploitation by each point around its current position. Updating is done in two steps to change the position of each solution. The first step mutates the elements of solution points and in the second step the whole solution is changed. Updating process is carried out on the basis of a probability assigned to each solution such that better solutions have lesser probability of change and higher chances of being retained unaltered.

\section{IMPROVED STOCASTIC FRACTAL SEARCH ALGORITHM (ISFSA)}

The initial solutions are generated according to the equation depicted below within specified upper limit (UB) and lower limit (LB)

$$
r_{i}=L B+F *(U B-L B)
$$

where $F$ is the user defined parameter.

Stochastic Fractal Search has two important processes called diffusion and updating which are discussed as below.

\section{A. Diffusion Process}

Here points are generated in the search space to enhance exploitation capability of an algorithm that increases the probability of finding local minima.

To generate different points Gaussian walks is utilized as per the (20) and (21).

$$
\begin{gathered}
G W_{1}=\operatorname{gaussian}\left(\mu_{B P}, \sigma\right)+\varepsilon \times B P-\varepsilon^{\prime} \times r_{i} \\
G W_{2}=\operatorname{gaussian}\left(\mu_{q}, \sigma\right)
\end{gathered}
$$

Where $\varepsilon$ and $\dot{\varepsilon}$ are uniformly distributed random numbers between 0 and $1, r_{i}$ and $B P$ are $i^{\text {th }}$ point and best point in the group respectively. $\mu_{B P}=|B P|$ and $\mu_{q}=\left|r_{i}\right|$, 
$\sigma$ is the standard deviation represented as below.

$$
\sigma=\frac{\log (g)}{g} \times\left(r_{i}-B P\right)
$$

The factor $\frac{\log (g)}{g}$ decreases the size of the Gaussian jumps as iteration $(\mathrm{g})$ growths during simulation.

\section{B. Updating Process}

After initialization as in (19) all points in the search space, their fitness is evaluated and the best point (BP) is identified, then this point is diffused around the initial position and different points are generated by (20) or Eq. (21).

Then ranking process is carried out for all points based on their fitness. On the basis of fitness of points probabilities are assigned to all these points uniformly to these points according to the (23).

$$
r_{a i}=\frac{\operatorname{rank}\left(r_{i}\right)}{N}
$$

Where, $\operatorname{rank}\left(r_{i}\right)$ is the $r$ ank of point $r_{i}$ among the other points in the group and $\mathrm{N}$ is the number of points in the group.

For each point $r_{i}$ in group based on either condition $r_{a i}<\varepsilon$ is satisfied or not, the $j_{t h}$ component of $r_{i}$ is updated according to the equation below otherwise it remains unchanged.

$$
r_{i}^{\prime}=r_{r}(j)-\epsilon \times\left(r_{t}(j)-r_{i}(j)\right)
$$

$r_{i}^{\prime}$ is the new modified position of $r_{i}, r_{r}$ and $r_{t}$ are random selected points.

In second updating phase, the positions of all points are modified with respect to the position of other points in the group. It helps to improve the quality of exploration.

All points obtained from the first updating process are ranked again according to the (23) If $r_{a i}<\varepsilon$ for the $i^{t h}$ position is held for a new point $r_{i}^{\prime}$, the current position of $r_{i}^{\prime}{ }_{\mathrm{i}}^{\prime}$ is modified according to the (25) and (26) as depicted below otherwise remains unchanged.

$$
\begin{aligned}
& r_{i}^{\prime \prime}=r_{i}^{\prime}+\varepsilon^{\prime} \times\left(r_{t}^{\prime}-B P\right) \text { if } \quad \varepsilon^{\prime} \leq 0.5 \\
& r_{i}^{\prime \prime}=r_{i}^{\prime}+\varepsilon^{\prime} \times\left(r_{t}^{\prime}-\left(r_{r}^{\prime}\right) \text { if } \quad \varepsilon^{\prime}>0.5\right.
\end{aligned}
$$

Where $r_{t}^{\prime}$ and $r_{r}^{\prime}$ are random selected points obtained from the first updating process, $\varepsilon^{\prime}$ is random number generated by the Gaussian distribution. If the fitness of new solution is found to be better, then only $r_{i}^{\prime \prime}$ is replaced by $r_{i}^{\prime}$.

\section{TOPSIS}

TOPSIS stands for technique for order preference by similarity to an ideal solution (TOPSIS) [23]. TOPSIS is a tool to find the best compromise solution between the conflicting objectives. TOPSIS tries to find the solution which is nearer to the ideal solution. Working of TOPSIS is summed up here-under in steps [24].

Step-1 In step-1 the normalized decision matrix is obtained as mentioned below:

$$
a_{i j}=\frac{b_{i j}}{\sqrt{\operatorname{sum}\left(b_{i j}^{2}\right)}} \text { for } i=1,2,---k ; j=1,2,--l
$$

Where, $a_{i j}$ and $b_{i j}$ are normalized and original decision matrix and $k$ is the number of alternative solution and $l$ is the number of alternatives.

Step-2 In step-2 normalized weighted matrix is calculated from the normalized decision matrix as mentioned in step-1, which is calculated from (28)

$$
\theta_{i j}=W_{j} \times a_{i j}
$$

$W_{j}$ is a matrix in which weights are assigned to the objectives and $\theta_{i j}$ is the weighted normalized decision matrix.

Step-3 In step-3 positive and negative ideal solution are identified as per(29) and (30) respectively.

$$
P^{*}=\left[\theta_{1}^{*}, \theta_{2}^{*},---\theta_{n}^{*}\right]
$$

and

$$
\begin{gathered}
\theta_{j}^{*}=\left\{\max \left(\theta_{i j}\right) \quad \text { if } j \in J ; \min \left(\theta_{i j}\right) \text { if } j \in J^{\prime}\right\} \\
P^{\prime}=\left[\theta_{1}^{\prime}, \theta_{2}^{\prime},---\theta_{n}^{\prime}\right]
\end{gathered}
$$

and

$$
\theta_{j}^{\prime}=\left\{\min \left(\theta_{i j}\right) \text { if } j \in J ; \max \left(\theta_{i j}\right) \text { if } j \in J^{\prime}\right\}
$$

Step-4 In step-4 geometric distances from the positive and negative ideal solutions are calculated as per the (31) and (32)

$$
\begin{gathered}
\mu_{i}^{*}=\sqrt{\left.\sum_{j=1}^{l}\left(\theta_{i j}-\theta_{j}^{*}\right)^{2}\right)} \\
\mu_{i}^{\prime}=\sqrt{\sum_{j=1}^{l}\left(\theta_{i j}-\theta_{j}^{\prime}\right)^{2}}
\end{gathered}
$$

Step-5 In this step TOPSIS rank is calculated with respect to the closeness of ideal solution as:

$$
\mu_{i}=\frac{\mu_{i}^{\prime}}{\mu_{i}^{*}+\mu_{i}^{\prime}}
$$

Higher values of TOPSIS rank indicates that the equivalent solution is close to the ideal solution. 


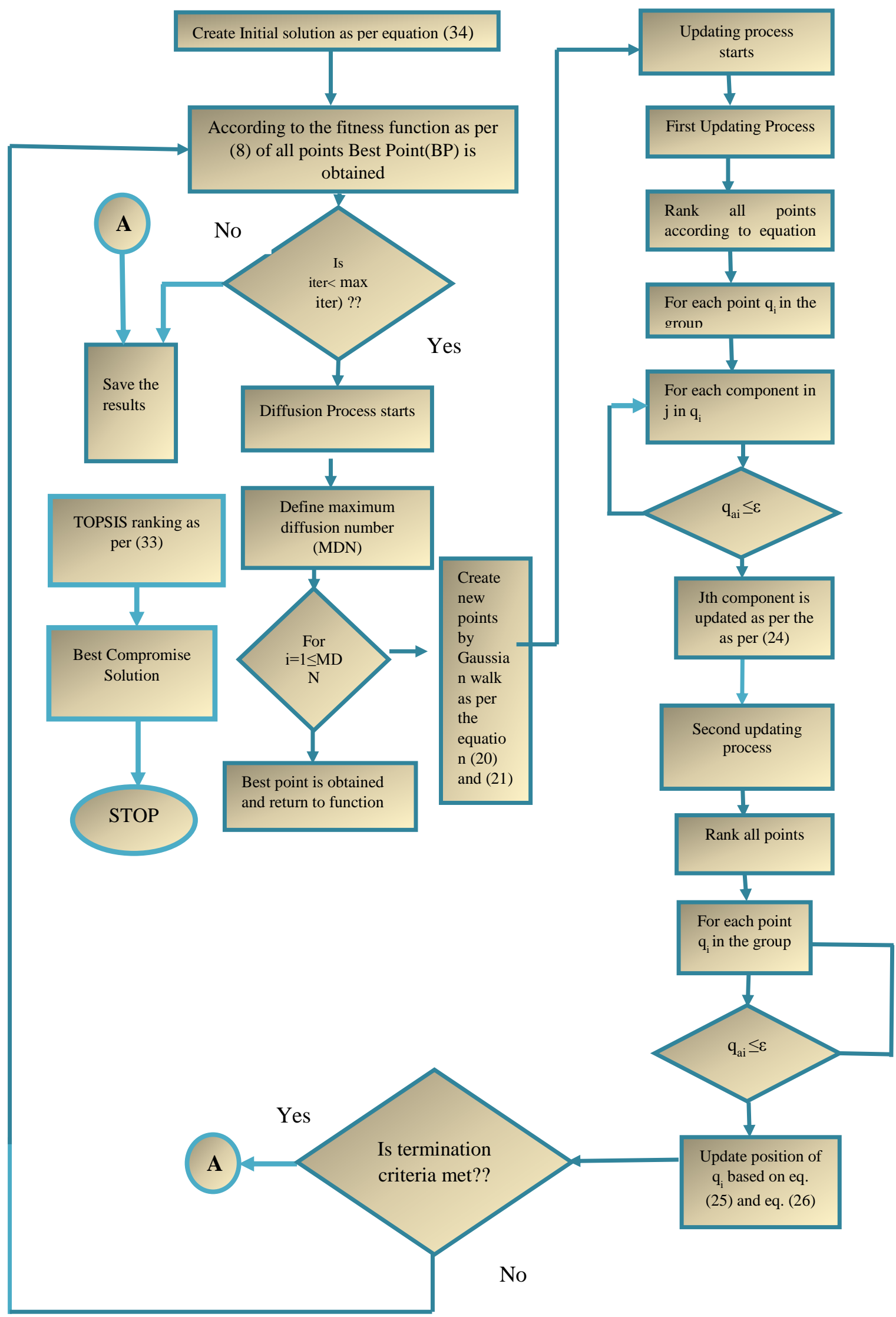

Fig.1. Implentation of flow chart of ISFSA in MOOD problem 


\section{IMPLEMENTATION OF ISFSA FOR SOLUTION OF Multi OBJECTIVE OPTIMAL DisPatCh}

In this section implementation of ISFSA is explained for economic emission dispatch problem. The step wise solution is given below.

Step-1 In this step all the random solution (Points) are evaluated as per the (34).

$$
\text { Points }=P_{i}^{\text {min }}+\mathrm{F} \times\left(P_{i}^{\text {max }}-P_{i}^{\text {min }}\right)
$$

Where $P_{i}^{\max }$ and $P_{i}^{\text {min }}$ are the maximum and minimum power limits of $i^{\text {th }}$ generator and $\mathrm{F}$ is scale factor.

Step-2 Fitness of points generated in step-1 is calculated as per the (8) by satisfying all the operating constraints given by (9), (11) and(16). After ranking by (23) best points are evaluated according to their fitness.

The TOPSIS ranking is done as per (33) to get best compromise solution(BCS). For TOPSIS ranking single objective function is considered alone to minimized among the multi-objective function by assigning weight factor for that particular as 1 and for other objective remains zero. On the other hand, if all objective function among ' $x$ ' objectives required to be minimizes at a time, the weight assigned to each objective is considered as $1 / x$

Step-3 The best points obtained as in step 2 are diffused around its neighbouring position to generate other points in the search space as per (20) and (21).

Step-4 Fitness of diffused points of step-3 are evaluated again by (8) and has to satisfy operating constraints depicted in (9), (11) and(16) and re-ranking has been done.

Step-5 updating process is carried out by(24).

They are ranked again as in step-2, till the termination criterion has not been met, If the termination criterion is not met then from step-1 to step-5 are repeated again. Whole solution procedure is depicted using flowchart in "Fig. 1".

\section{RESULT AND DISCUSSION}

In order to validate the potential ISFSA is applied to six different standard test systems. These optimization approaches are implemented using MATLAB R2009a and the system configuration is Intel core i5 processor with $2.20 \mathrm{GHz}$ and $4 \mathrm{~GB}$ RAM.

\section{A. Desescription Of Test Systems \\ 1) Test system-1}

It consists of six thermal generating units [7]. The fuel cost and emission function is convex in nature. Transmission losses are also taken into the account. The system demand is $1200 \mathrm{MW}$.

\section{2) Test system -2}

Here a solar plant with maximum power output of 50 MW and six thermal units are considered for analysis. Fuel cost, emission transmission loss and power demand are set as in test system 1 .

\section{3) Test system -3}

In this test system having six thermal units, one solar power plant and one wind farm. The cost coefficient for wind farm considered as $k_{r}=1, k_{p}=5$, rated power output $\left(P_{\text {wind }}^{R}\right)$ as $120 \mathrm{MW}$. The other constants are $u_{c i}=5$, $u_{c o}=45$ and $u_{\mathrm{r}}=15$. The shape and scale factor as 1 and 15 respectively. Fuel cost, emission, transmission loss and power demand are set similar to test system 1.

\section{4) Test system -4}

This test system has ten thermal units with valve point loading (VPL) effects. The entire Fuel cost, emission and B-loss coefficients data were adopted from [8]. Power Demand for this is $2000 \mathrm{MW}$.

\section{5) Test system -5}

In this test system there are ten thermal units with one solar power plant. Fuel cost, emission transmission loss and power demand are set as in test system 4 . The solar power plant is same in test system -2 .

\section{6) Test system -6}

This test system has ten thermal units, one solar power plant and one wind farm. The solar power plant is same as in test system -2 . The data related to wind farm is similar to test case 3 . Fuel cost, emission, transmission loss and power demand are set similar to test system 4 .

\section{B. Best Cost Solution}

The optimum dispatch solutions for test system 1,2 and 3 in "Table 1.", and for test system 4,5 and 6 in "Table 2. ." For test system 1 , the outcome of simulation result obtained by SFSA and the proposed ISFSA in terms of best cost is found to be $63975.9724 \$ / \mathrm{hr}$ and 63975.7780 $\$ / \mathrm{hr}$ respectively, the corresponding dispatch solution is presented in "Table 1.". 
Table 1. Optimum dispatch solution obtained by SFSA and ISFSA with power demand of $1200 \mathrm{MW}$

\begin{tabular}{|c|c|c|c|c|c|c|}
\hline \multirow{2}{*}{ Units } & \multicolumn{2}{|c|}{ Test system-1 } & \multicolumn{2}{c|}{ Test system-2 } & \multicolumn{2}{c|}{ Test ststem-3 } \\
\cline { 2 - 7 } & SFSA & ISFSA & SFSA & ISFSA & SFSA & ISFSA \\
\hline P1 & 81.1157 & 80.7540 & 60.1524 & 59.6993 & 45.3875 & 45.1369 \\
\hline P2 & 87.3417 & 87.6918 & 55.4594 & 55.8831 & 34.4775 & 34.0697 \\
\hline P3 & 209.9996 & 209.9999 & 209.9999 & 209.9999 & 193.2754 & 194.3031 \\
\hline P4 & 224.9998 & 224.9999 & 224.9952 & 224.9999 & 195.8479 & 197.2366 \\
\hline P5 & 324.9984 & 324.9999 & 324.9961 & 324.9999 & 325.0000 & 325.0000 \\
\hline P6 & 324.9991 & 324.9999 & 324.9880 & 324.9999 & 323.5296 & 324.9995 \\
\hline$P_{P V}$ & N. A & N. A & 49.9521 & 49.9521 & 49.9521 & 49.9521 \\
\hline$P_{\text {wind }}$ & N. A. & N. A. & N. A. & N. A. & 116.0625 & 111.7116 \\
\hline TC $(\$ / h r)$ & N.A. & N.A. & N. A & N. A & 60797.1464 & 60796.6458 \\
\hline$C_{\text {under }}$ & N. A & N. A & N. A & N. A & 7.2533 & 15.5508 \\
\hline$C_{\text {over }}$ & N. A & N. A & N. A & N. A & 239.3079 & 225.8507 \\
\hline Th. C $(\$ / h r)$ & 63975.9724 & 63975.7780 & 60762.0532 & 60761.7053 & 60550.5852 & 60555.2443 \\
\hline Emission(ton/hr) & 1360.03320 & 1360.0657 & 1311.1350 & 1311.217 & 1176.6295 & 1184.9758 \\
\hline$P_{\mathrm{L}}(\mathrm{MW})$ & 53.4498 & 53.4460 & 50.54258 & 50.5349 & 83.5325 & 82.4095 \\
\hline
\end{tabular}

TC:Total Cost,Th. C: Thermal Cost, NA: Not Applicable

The results have been compared with Differential Evolution (DE) [3], Quasi -oppositional Teacher Learner based Optimization (QTLBO) [7] and most recently reported method Backtracking Search Algorithm (BSA) [10] and presented in "Table 3.". Here it is observed that the best cost solution obtained by SFSA is also found to be better than other reported method. Also comparing test system 1 and 2 i.e. with integration of solar power the operating cost reduced by $5.02 \%$ and while comparing test system 1 and 3 i.e. by integration of both solar and wind power operating cost reduced by $4.97 \%$.

Similarly, for test system 4, outcome of simulation results by SFSA and ISFSA have compared with results reported using (QTLBO) [7], RCCRO [9] and (BSA) [10]. Here also results obtained by ISFSA are found to be superior. While comparing test system 4 and 5 , test system 4 and 6 the total operating cost reduced by $2.97 \%$ and $5.18 \%$ respectively.

Table 2. Optimum dispatch solution obtained by SFSA and ISFSA with power demand of $2000 \mathrm{MW}$

\begin{tabular}{|c|c|c|c|c|c|c|}
\hline \multirow{2}{*}{ Units } & \multicolumn{2}{|c|}{ Test Case-4 } & \multicolumn{2}{c|}{ Test Case-5 } & \multicolumn{2}{c|}{ Test Case-6 } \\
\cline { 2 - 7 } & SFSA & ISFSA & SFSA & ISFSA & SFSA & ISFSA \\
\hline P1 & 55.0000 & 55.0000 & 54.9875 & 55.0000 & 55.0000 & 55.0000 \\
\hline P2 & 80.0000 & 80.0000 & 79.9970 & 80.0000 & 78.9443 & 78.9081 \\
\hline P3 & 106.9412 & 106.9369 & 94.8682 & 94.6362 & 82.1450 & 82.1833 \\
\hline P4 & 100.5775 & 100.5775 & 87.5323 & 87.6698 & 74.5782 & 74.5407 \\
\hline P5 & 81.4969 & 81.5011 & 71.4956 & 71.4964 & 61.3737 & 61.3689 \\
\hline P6 & 83.0231 & 83.0233 & 70.0844 & 70.0000 & 70.0000 & 70.0000 \\
\hline P7 & 300.0000 & 300.0000 & 298.0291 & 297.9021 & 264.7241 & 264.6792 \\
\hline P8 & 340.0000 & 340.0000 & 336.7483 & 337.0262 & 298.2191 & 298.4907 \\
\hline P9 & 470.0000 & 470.0000 & 469.9966 & 470.0000 & 457.0549 & 456.8658 \\
\hline P10 & 470.0000 & 470.0000 & 469.9886 & 470.0000 & 469.9998 & 470.0000 \\
\hline$P_{P V}$ & N. A. & N. A. & 49.9521 & 49.9521 & 49.9521 & 49.9521 \\
\hline$P_{\text {wind }}$ & N. A & N. A & N. A & N. A & 120.0000 & 120.0000 \\
\hline TC $(\$ / h r)$ & N.A. & N.A. & N.A. & N.A. & 105715.4103 & 105715.3996 \\
\hline$C_{\text {under }}$ & N. A & N. A & N. A & N. A & 0.0000 & 0.0001 \\
\hline$C_{\text {over }}$ & N. A & N. A & N. A & N. A & 251.7421 & 251.7419 \\
\hline Th. C $\$ / h r)$ & 111497.6308 & 111497.6225 & 108185.5777 & 108185.4127 & 105463.6682 & 105463.6576 \\
\hline $\begin{array}{c}\text { Emission } \\
\text { ton/hr }\end{array}$ & 4572.1869 & 4572.1854 & 4398.6985 & 4399.1084 & 3782.8370 & 3782.8586 \\
\hline Ploss $(\mathrm{MW})$ & 87.0388 & 87.0388 & 83.68291 & 83.6828 & 81.9912 & 81.9888 \\
\hline
\end{tabular}


Table 3. Comparison of results in terms of best cost solution

\begin{tabular}{|c|c|c|c|c|}
\hline \multirow{3}{*}{ Method } & \multicolumn{2}{|c|}{ Test sytem-1 } & \multicolumn{2}{|c|}{ Test sytem-4 } \\
\hline & \multicolumn{4}{|c|}{ Best Cost Solution } \\
\hline & Cost $(\$ / h)$ & Emission (ton/h) & Cost $(\$ / h)$ & Emission (ton/h) \\
\hline $\mathrm{DE}[3]$ & 64083.0000 & 1345.6000 & NA & NA \\
\hline QTLBO[7] & 63977.0000 & 1360.1000 & 111498.0000 & 4568.7000 \\
\hline BSA [10] & 63976.0000 & 1360.1000 & 111497.6308 & 4572.1939 \\
\hline RCCRO[9] & NA & NA & 111497.6319 & 4571.9552 \\
\hline SFSA & 63975.9724 & 1360.03320 & 111497.6308 & 4572.1869 \\
\hline ISFSA & 63975.7780 & 1360.0657 & 111497.6225 & 4572.1854 \\
\hline
\end{tabular}

\section{Best Emission Solution}

Optimum dispatch solution corresponding to best emission obtained by SFSA and ISFSA have been presented in "Table 4." for test system 1,2 and 3 and in "Table 5" for test system 4,5 and 6 respectively. The comparison of results have made with different reported method as Differential Evolution (DE) [3], Quasi oppositional Teacher Learner based Optimization (QTLBO) [7] and most recently reported method Backtracking Search Algorithm (BSA) [10] for test system 1 and presented in "Table 6.".
Also results are compared with QTLBO [7], BSA [10] and RCCRO [9] for test system-4. In both the test systems results obtained by ISFSA are found to be superior to other methods. Comparing test system 1 and 2 , test system 4 and 5 it is observed that the total emission reduced by $4.87 \%$ and $9.14 \%$ respectively by solar thermal integration. While Comparing test system 1 and 3 , test system 4 and 6 there is much reduction in total emission by $16.62 \%$ and $22.46 \%$ by integrated solar-wind thermal power generating system.

Table 4. Optimum emission solution obtained by SFSA and ISFSA with power demand of $1200 \mathrm{MW}$

\begin{tabular}{|c|c|c|c|c|c|c|}
\hline \multirow{2}{*}{ Units (MW) } & \multicolumn{2}{|c|}{ Test Case-1 } & \multicolumn{2}{c|}{ Test Case-2 } & \multicolumn{2}{c|}{ Test Case-3 } \\
\cline { 2 - 7 } & SFSA & ISFSA & SFSA & ISFSA & SFSA & ISFSA \\
\hline $\mathbf{P 1}$ & 124.9997 & 124.9999 & 124.9808 & 124.9996 & 124.9999 & 125.0000 \\
\hline $\mathbf{P 2}$ & 149.9974 & 150.0000 & 149.9448 & 149.9995 & 149.9998 & 149.9999 \\
\hline $\mathbf{P 3}$ & 201.1010 & 201.4089 & 190.8899 & 189.9192 & 171.8504 & 171.7912 \\
\hline $\mathbf{P 4}$ & 199.6312 & 199.2479 & 188.2610 & 188.0065 & 170.4498 & 170.4243 \\
\hline $\mathbf{P 5}$ & 287.5393 & 287.9689 & 270.03172 & 272.1069 & 246.0136 & 246.01885 \\
\hline $\mathbf{P 6}$ & 286.8925 & 286.5307 & 271.6166 & 270.7150 & 244.9751 & 244.9866 \\
\hline $\boldsymbol{P}_{\boldsymbol{P V}}$ & N. A & N. A & 49.9521 & 49.9521 & 49.9521 & 49.9521 \\
\hline $\boldsymbol{P}_{\boldsymbol{w i n d}}$ & N. A. & N. A. & N. A. & N. A. & 120.0000 & 120.0000 \\
\hline $\boldsymbol{C}_{\text {under }}$ & N. A & N. A & N. A & N. A & 0.0000 & 0.0000 \\
\hline $\boldsymbol{C}_{\boldsymbol{o v e r}}$ & N. A & N. A & N. A & N. A & 251.7421 & 251.7420 \\
\hline TC(\$/hr) & N.A. & N.A. & N. A & N. A & 63655.6045 & 63655.4192 \\
\hline Th. C(\$/hr) & 65994.9958 & 65992.4503 & 63279.6550 & 63289.8680 & 63403.8624 & 63403.6771 \\
\hline Emission(ton/hr) & 1240.7033 & 1240.6545 & 1127.5775 & 1127.22010 & 962.0030 & 962.0028 \\
\hline $\mathbf{P}_{\text {Loss }}(\mathbf{M W )}$ & 50.1143 & 50.1565 & 45.6415 & 45.6932 & 78.2407 & 78.2426 \\
\hline
\end{tabular}

D. Best Compromise Solution (BCS) and Pareto Optimal Solution

The Cost and emissions are now simultaneously optimized with equal weight to both objectives. In this paper, the two objectives were selected on the basis of TOPSIS ranking using (35). A large number of Pareto optimal solutions were obtained for MOOD problem. They are plotted in "Fig. 2" for two objectives at a time for test system 1 to 3 and in "Fig. 3" for test system 4 to 6

The BCS using ISFSA and TOPSIS is found to be $64672.55911 \$ / \mathrm{hr}, 1295.37772 \mathrm{ton} / \mathrm{hr}$ and 112821.97420 $\$ / \mathrm{hr}, 4185.30993 \mathrm{ton} / \mathrm{hr}$ for test system 1 and test system 4 respectively. Also comparison of results is made with DE [3], QTLBO [7], BSA [10], RCCRO [9] for respective test system and presented in "Table 7.". 
Table 5. Optimum emission solution obtained by SFSA and ISFSA with power demand of $2000 \mathrm{MW}$

\begin{tabular}{|c|c|c|c|c|c|c|}
\hline \multirow[t]{2}{*}{$\begin{array}{l}\begin{array}{l}\text { Units } \\
\text { (MW) }\end{array} \\
\end{array}$} & \multicolumn{2}{|c|}{ Test Case-4 } & \multicolumn{2}{|c|}{ Test Case-5 } & \multicolumn{2}{|c|}{ Test Case-6 } \\
\hline & SFSA & ISFSA & SFSA & ISFSA & SFSA & ISFSA \\
\hline P1 & 54.9999 & 55.00000 & 54.99994 & 55.0000 & 54.9868 & 55.0000 \\
\hline P2 & 79.9998 & 80.00000 & 78.98101 & 79.2937 & 73.0167 & 73.4449 \\
\hline P3 & 81.1360 & 81.13442 & 79.03569 & 79.1279 & 72.2334 & 73.2071 \\
\hline $\mathbf{P 4}$ & 81.3664 & 81.36366 & 78.84822 & 79.3611 & 73.2677 & 73.3615 \\
\hline P5 & 159.9999 & 160.00000 & 159.99958 & 160.0000 & 159.9651 & 160.0000 \\
\hline P6 & 239.9999 & 240.00000 & 239.99987 & 240.0000 & 239.9998 & 240.0000 \\
\hline P7 & 294.5061 & 294.48525 & 279.00572 & 282.6587 & 249.8656 & 251.5241 \\
\hline P8 & 297.2489 & 297.26931 & 284.47932 & 284.9692 & 251.4523 & 251.6608 \\
\hline P9 & 396.7685 & 396.76604 & 386.22658 & 384.0072 & 367.9356 & 364.2236 \\
\hline P10 & 395.5690 & 395.57647 & 385.76835 & 382.8394 & 362.5558 & 362.7982 \\
\hline $\boldsymbol{P}_{P V}$ & N. A. & N. A. & 49.9521 & 49.9521 & 49.9521 & 49.9521 \\
\hline$P_{\text {wind }}$ & N. A & N. A & N. A & N. A & 119.9976 & 120.0000 \\
\hline $\begin{array}{c}\text { TC } \\
(\$ / h r)\end{array}$ & N.A. & N.A. & N.A. & N.A. & 111302.6126 & 111313.3125 \\
\hline$C_{\text {under }}$ & N. A & N. A & N. A & N. A & 0.0043 & 0.0000 \\
\hline$C_{\text {over }}$ & N. A & N. A & N. A & N. A & 251.7345 & 251.7420 \\
\hline $\begin{array}{l}\text { Th.C } \\
(\$ / h r)\end{array}$ & 116412.5449 & 116412.44313 & 113369.06395 & 113391.0302 & 111050.8738 & 111061.5705 \\
\hline $\begin{array}{c}\text { Emission } \\
\text { (ton/hr) }\end{array}$ & 3932.1990 & 3932.19893 & 3742.65330 & 3742.4830 & 3286.5676 & 3286.3592 \\
\hline Ploss & 81.5957 & 81.5952 & 77.29533 & 77.2093 & 75.2285 & 75.1723 \\
\hline
\end{tabular}

Table 6. Comparison of best emission solution

\begin{tabular}{|c|c|c|c|c|}
\hline \multirow{2}{*}{ Method } & \multicolumn{2}{|c|}{ Test sytem-1 } & \multicolumn{2}{c|}{ Test sytem-4 } \\
\cline { 2 - 5 } & \multicolumn{3}{|c|}{ Best emission solution } \\
\cline { 2 - 5 } & Cost $(\$ / \mathrm{h})$ & Emission $($ ton/h) & Cost $(\$ / \mathrm{h})$ & Emission $($ ton/h) \\
\hline DE [3] & 65991.0000 & 1240.7000 & NA & NA \\
\hline QTLBO[7] & 65992.0000 & 1240.7000 & 116412.0000 & 3932.2000 \\
\hline BSA[10] & 65992.0000 & 1240.6000 & 116412.4441 & 3932.2432 \\
\hline RCCRO[9] & NA & NA & 116412.4441 & 3932.2433 \\
\hline SFSA & 65994.9958 & 1240.7033 & 116412.5449 & 3932.1990 \\
\hline ISFSA & 65992.4503 & 1240.6545 & 116412.4431 & 3932.1989 \\
\hline
\end{tabular}

Table 7. Comparison of best compromise solution

\begin{tabular}{|c|c|c|c|c|}
\hline \multirow{2}{*}{ Method } & \multicolumn{3}{|c|}{ Test sytem-1 } & \multicolumn{2}{c|}{ Test sytem-4 } \\
\cline { 2 - 5 } & \multicolumn{3}{|c|}{ Best compromise solution } \\
\cline { 2 - 5 } & Cost $(\$ / \mathrm{h})$ & Emission (ton/h) & Cost $(\$ / \mathrm{h})$ & Emission (ton/h) \\
\hline DE [3] & 64843.0000 & 1286.0000 & NA & NA \\
\hline QTLBO[7] & 64912.0000 & 1281.0000 & 113460.0000 & 4110.2000 \\
\hline BSA [10] & 64766.8227 & 1289.5856 & 113126.7514 & 4146.0000 \\
\hline RCCRO[9] & NA & NA & 113355.7454 & 4121.0684 \\
\hline ISFSA & 64672.5591 & 1295.3777 & 112821.9742 & 4185.3099 \\
\hline
\end{tabular}


Table 8. Optimum dispatch solution for best compromise solution obtained by ISFSA and TOPSIS with power demand of $1200 \mathrm{MW}$

\begin{tabular}{|c|c|c|c|}
\hline \multirow{2}{*}{ UNIT(MW) } & Test Case-1 & Test Case-2 & Test Case-3 \\
\cline { 2 - 4 } & ISFSA & ISFSA & ISFSA \\
\hline P1 & 101.8850 & 81.6882 & 74.6999 \\
\hline P2 & 114.3664 & 87.8004 & 78.1106 \\
\hline P3 & 208.0462 & 203.8795 & 189.8932 \\
\hline P4 & 207.7425 & 204.2947 & 189.5119 \\
\hline P5 & 311.4096 & 312.3881 & 290.7455 \\
\hline P6 & 308.4191 & 308.6688 & 288.4332 \\
\hline$P_{P V}$ & N. A. & 49.9521 & 49.9521 \\
\hline$P_{\text {wind }}$ & N. A & N. A & 120.0000 \\
\hline$C_{\text {under }}$ & N. A & N. A & 0.0001 \\
\hline$C_{\text {over }}$ & N. A & N. A & 251.7419 \\
\hline Total Cost $(\$ h r)$. & N.A. & N. A & 61227.9677 \\
\hline Thermal Cost $(\$ / h r)$. & 64670.2559 & 61193.8879 & 60976.2257 \\
\hline Emission(ton/hr.) & 1295.5246 & 1227.6890 & 1054.8410 \\
\hline$P_{\mathrm{L}}(\mathrm{MW})$ & 51.8710 & 48.6696 & 81.3464 \\
\hline
\end{tabular}

Table 9. Optimum dispatch solution for best compromise solution obtained ISFSA and TOPSIS with power demand of 2000 MW

\begin{tabular}{|c|c|c|c|}
\hline Units & Test Case-4 & Test Case-5 & Test Case-6 \\
\hline P1 & 55.0000 & 55.00000 & 55.0000 \\
\hline P2 & 80.0000 & 80.00000 & 76.9375 \\
\hline P3 & 86.3390 & 83.81089 & 77.6008 \\
\hline P4 & 84.6266 & 82.1782 & 75.9967 \\
\hline P5 & 130.0995 & 128.7719 & 117.0431 \\
\hline P6 & 147.7002 & 145.5013 & 129.5793 \\
\hline P7 & 300.0000 & 292.4820 & 266.6872 \\
\hline P8 & 319.5752 & 310.7495 & 280.3779 \\
\hline P9 & 439.1793 & 424.5143 & 412.8025 \\
\hline P10 & 442.0893 & 427.1345 & 416.4886 \\
\hline$P_{P V}$ & N. A & 49.9521 & 49.9521 \\
\hline$P_{\text {wind }}$ & N. A & N. A & 120.0000 \\
\hline$C_{\text {under }}$ & N. A & N. A & 0.0000 \\
\hline$C_{\text {over }}$ & N. A & N. A & 251.7420 \\
\hline Total Cost $(\$ h r)$ & N.A. & N.A. & 106628.0411 \\
\hline Thermal Cost $(\$ / h r)$ & 112821.9742 & 109674.9568 & 106879.7832 \\
\hline Emission(ton/hr) & 4185.3099 & 3976.3318 & 3494.2613 \\
\hline$P_{\mathrm{L}(\mathrm{Mw})}$ & 84.6096 & 80.09498 & 78.4657 \\
\hline
\end{tabular}

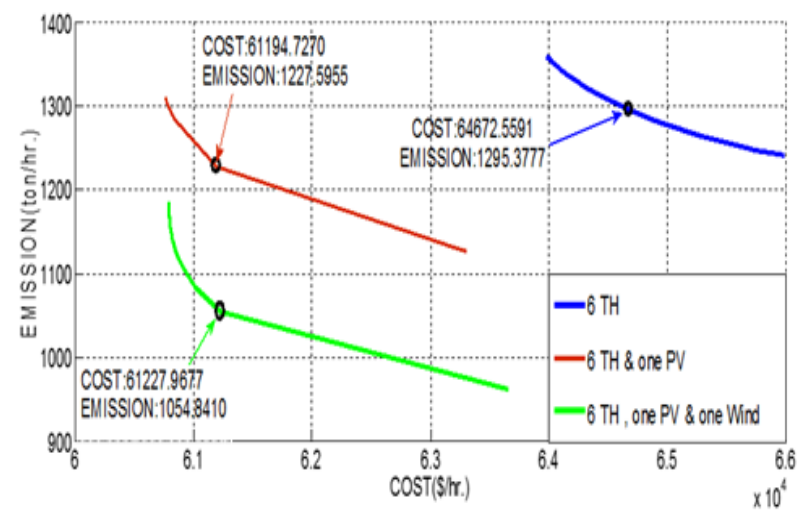

Fig.2. Optimal pareto front for test system-1, 2 and 3 obtained by ISFSA.

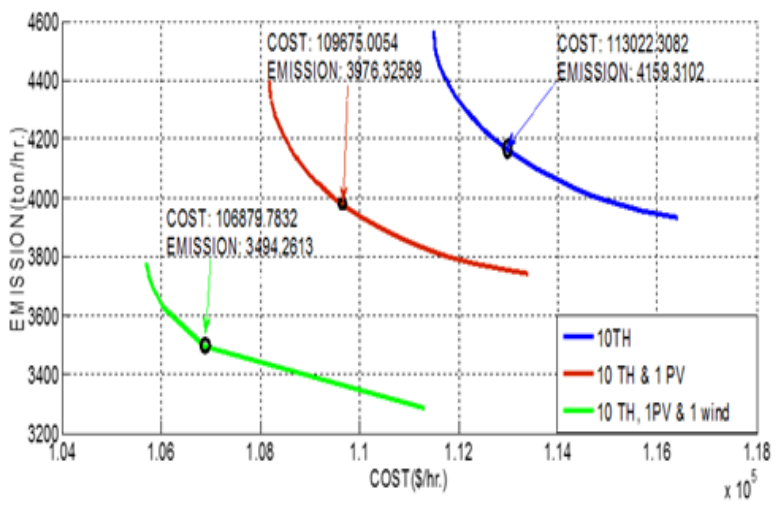

Fig.3. Optimal pareto front for test system-4, 5 and 6 obtained by ISFSA. 


\section{VII-A. SELCETION OF PARAMETER}

As SFSA is a heuristic method, it also requires optimal tuning parameter to discover global optima solution. In order to investigate best optimal tuning parameter of SFSA, it is applied on the test system-4 having 10-unit test system with non convex fuel cost characteristic due to VPL effect. Twenty-five independent run were conducted with different start point (NP) and maximum diffusion number (MDN). The statistical results are tabulated in "Table.10.". Here it is observed that optimum cost is achieved by $\mathrm{NP}=50$ and $\mathrm{MDN}=2$ with comparatively low standard deviation (SD) of 0.0033 , therefore selected for simulation analysis.

Further considering $\mathrm{NP}=50, \quad \mathrm{MDN}=2$ simulation analysis was carried out by variation in scale factor on the same 10-unit test system over 25 repeated trails. The outcome of simulation result is tabulated in "Table 11(a).". Here it is observed that results in terms of cost, standard deviation and also the CPU time get improved with respect to SFSA technique. Comparison of convergence characteristics of SFSA and ISFSA is shown in "Fig. 4". Also the convergence characteristics of ISFSA for thermal, solar-thermal and solar-wind-thermal system described above as test system 4,5 and 6 is plotted in "Fig 5"

Table 10. Determination of optimal tuning parameter for SFSA

\begin{tabular}{|l|l|l|l|l|l|l|}
\hline NP & MDN & $\begin{array}{l}\text { Min Cost } \\
(\text { S/hr. })\end{array}$ & $\begin{array}{l}\text { Ave Cost } \\
(\text { \$hr. })\end{array}$ & $\begin{array}{l}\text { Max Cost } \\
(\$ / h r .)\end{array}$ & S.D & $\begin{array}{l}\text { Ave CPU } \\
\text { time (sec) }\end{array}$ \\
\hline \multirow{3}{*}{25} & 2 & 111497.6949 & 111497.8336 & 111498.0992 & 0.1508 & 5.41 \\
\cline { 2 - 8 } & 4 & 111497.6770 & 111497.8173 & 111497.9498 & 0.0862 & 9.83 \\
\cline { 2 - 7 } & 6 & 111497.6874 & 111497.8286 & 111498.1284 & 0.1449 & 10.56 \\
\hline \multirow{3}{*}{50} & 2 & $\mathbf{1 1 1 4 9 7 . 6 3 0 8}$ & $\mathbf{1 1 1 4 9 7 . 6 3 4 9}$ & $\mathbf{1 1 1 4 9 7 . 6 4 2 5}$ & $\mathbf{0 . 0 0 3 3}$ & 11.66 \\
\cline { 2 - 7 } & 4 & 111497.6525 & 111497.7004 & 111497.7459 & 0.0299 & 16.54 \\
\cline { 2 - 7 } & 6 & 111497.6451 & 111497.6805 & 111497.7298 & 0.0296 & 23.31 \\
\hline \multirow{3}{*}{100} & 2 & 111497.7189 & 111497.7820 & 111497.8846 & 0.0532 & 25.28 \\
\cline { 2 - 7 } & 4 & 111497.6854 & 111497.7596 & 111497.8711 & 0.0519 & 35.57 \\
\cline { 2 - 7 } & 6 & 111497.6688 & 111497.7786 & 111497.8979 & 0.0677 & 38.66 \\
\hline
\end{tabular}

Table 11(a). Effect of Scale factor (F)

\begin{tabular}{|l|l|l|l|l|l|}
\hline F & $\begin{array}{l}\text { Min Cost } \\
(\$ / h r .)\end{array}$ & $\begin{array}{l}\text { Ave Cost } \\
(\$ / h r .)\end{array}$ & $\begin{array}{l}\text { Max Cost } \\
(\$ / h r .)\end{array}$ & S.D & $\begin{array}{l}\text { Ave CPU } \\
\text { time }(\mathrm{sec})\end{array}$ \\
\hline 0.3 & 111497.6741 & 111497.7233 & 111497.8003 & 0.0517 & 11.82 \\
\hline 0.4 & 111497.6470 & 111497.6815 & 111497.7230 & 0.0308 & 11.62 \\
\hline $\mathbf{0 . 5}$ & $\mathbf{1 1 1 4 9 7 . 6 2 2 5}$ & $\mathbf{1 1 1 4 9 7 . 6 3 2 4}$ & $\mathbf{1 1 1 4 9 7 . 6 3 5 0}$ & $\mathbf{0 . 0 0 2 3}$ & $\mathbf{1 1 . 4 2}$ \\
\hline 0.6 & 111497.6478 & 111497.6818 & 111497.7190 & 0.0252 & 11.72 \\
\hline 0.7 & 111497.6619 & 111497.6938 & 111497.7741 & 0.0459 & 11.63 \\
\hline
\end{tabular}

F: Scale Factor

Table 11(b). Comparison of results obtained by ISFSA with SFS for test system 4

\begin{tabular}{|l|l|l|l|l|l|}
\hline Method & $\begin{array}{l}\text { Min Cost } \\
(\$ / \mathrm{hr} .)\end{array}$ & $\begin{array}{l}\text { Ave Cost } \\
(\$ / \mathrm{hr} .)\end{array}$ & $\begin{array}{l}\text { Max Cost } \\
(\$ / \mathrm{hr} .)\end{array}$ & S.D & $\begin{array}{l}\text { Ave CPU } \\
\text { time }(\mathrm{sec})\end{array}$ \\
\hline SFSA & 111497.6308 & 111497.6349 & 111497.64250 & 0.0033 & 11.66 \\
\hline ISFSA & 111497.6225 & 111497.63242 & 111497.63509 & 0.0023 & 11.42 \\
\hline
\end{tabular}

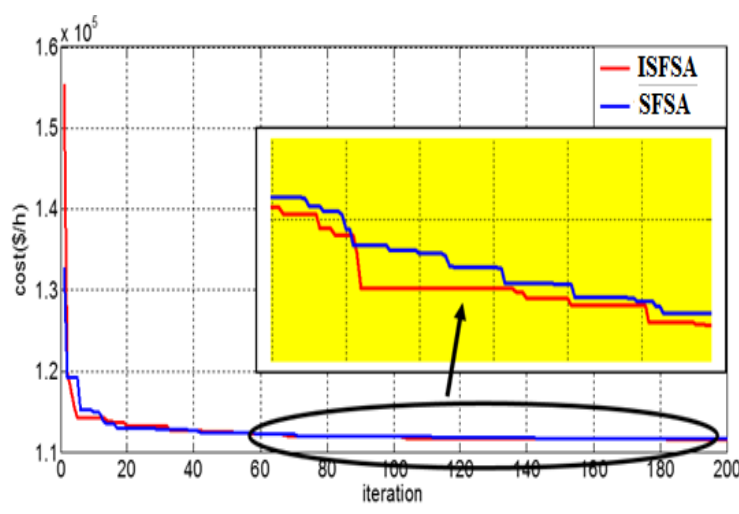

Fig.4. Comparison of convergence characteristics of SFSA and ISFSA for test system 4

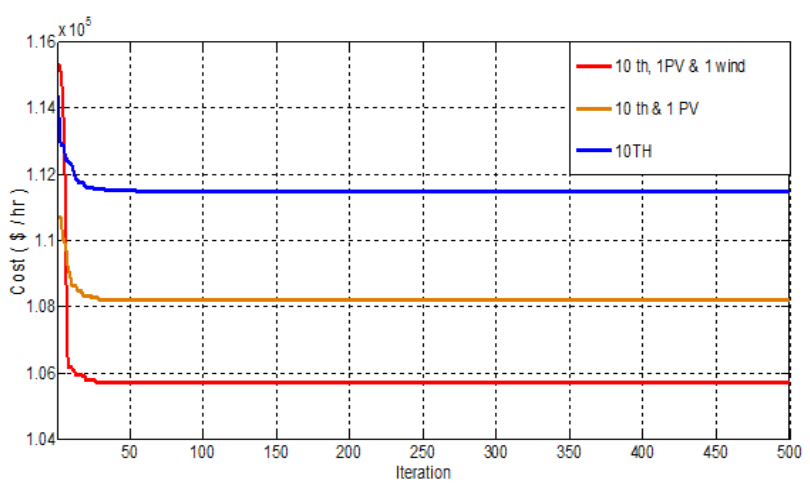

Fig.5. Convergence characteristic for test system-4, 5 and 6

\section{VII-B. COMPUTATIONAL EFFICIENCY}

The simulation time of SFSA and proposed ISFSA algorithms is compared for all six test cases in "Fig. 6". Considering complexity of test systems, the CPU time in rage of 6 to 12 seconds is obvious.

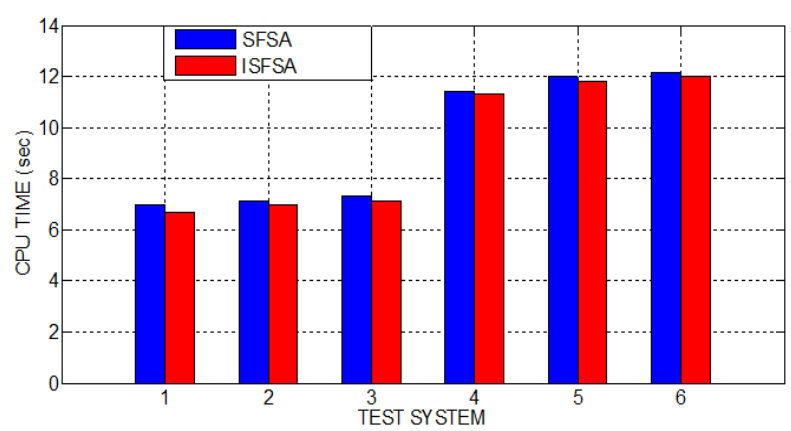

Fig.6. Average CPU time of ISFSA algorithm for different test systems

\section{CONCLUSION}

The paper proposed a novel improved stochastic fractal search for solution of MO problem of solar-wind-thermal system. The problem under consideration is solved for the simultaneous minimization of multiple objectives as cost and emission using a powerful newly proposed search 
technique, SFSA, which mimics the phenomenon of natural growth called fractal. A user defined scale factor is utilized to improve the exploration and exploitation capability of SFSA. The proposed ISFSA method effectively tackles complex practical constraints of thermal generation, and effect of WP uncertainty. The effect of solar, wind power integration on cost as well as emissions is also investigated. ISFSA produces the best results as compared to other recent reported methods for the tested problems. Finding the best solution for a MO problem is difficult as there are multiple attributes to consider, and therefore some kind of aggregation is necessary to reflect the merit of a solution. Many indices, based on different concepts, are available; however, each provides a different result. In this paper TOPSIS ranking index is considered for comprehensive merit criterion of the MO solar-wind-thermal system problem.

\section{ACKNOWLEDGMENT}

Authors are thankful to the Director, Madhav Institute of Technology \& Science, Gwalior (M.P) India for providing support and facilities to carry out this research work.

\section{REFERENCES}

[1] J Nanda., D.P. Kothari, K.S Linga Murthy, "Economic emission load dispatch through goal programming techniques", IEEE Trans. on Energy Conversion 3(1), (1988) 26-32

[2] C Palanichamy, N.S Babu, "Analytical solution for combined economic and emissions dispatch", Electric Power System Research 78, (2008) 1129-1137.

[3] M Basu. "Economic environmental dispatch using multiobjective differential evolution"Applied Soft Computing 11, (2011) 2845-2853

[4] M S Kaurav, H M Dubey, M Pandit, BK Panigrahi,Simulated annealing algorithm for combined economic and emission dispatch,in proc. IEEE Inter. Conf, ICACCN 2011,pp. 631-636.

[5] B.K Panigrahi, R.V.Pandi, S. Das, S.Das, "Multiobjective fuzzy dominance based bacterial foraging algorithm to solve economic emission dispatch problem" Energy 35, (2010) 4761-4770.

[6] N.Pandit, A. Tripathi, S.Tapaswi, M Pandit, "An improved bacterial foraging algorithm for combined static/dynamic environmental economic dispatch"Applied Soft Computing 12, (2012) 3500-3513.

[7] P K Roy, Sudipta Bhui "Multi-objective quasi oppositional teaching learning based optimization for economic emission load dispatch problem", Electrical Power and Energy systems:53(2013):937-948.

[8] U. Güvenç, Y.Sönmez, S.Duman, N.Yörükeren, "Combined economic and emission dispatch solution using gravitational search algorithm" Scientia Iranica D vol.19 no.6 pp.1754-1762 (2012)

[9] K.Bhattacharjee, A.Bhattacharya, S.H.Dey "Solution of Economic Emission Load Dispatch problems of power systems by Real Coded Chemical Reaction algorithm", Electrical and Energy systems vol.59,pp.176-187,(2014)

[10] K.Bhattacharjee, A.Bhattacharya, S.H.Dey, "Backtracking search optimization based economic environmental power dispatch problems". Electrical Power and Energy systems 73, 830-842. (2015)

[11] A J Wood, B F. Wallenberg, "Power Generation, Operation and Control". 1984, New York: Wiley.

[12] J. Hetzer, D. C. Yu, K. Bhattarai, "An Economic Dispatch Model Incorporating Wind Power", IEEE Trans. On Energy Conversion, vol. 23, no. 2, pp. 603-611, 2008.

[13] X. Liu, "Economic Load Dispatch Constrained by Wind Power Availability: A Wait-and-See Approach," IEEE Trans. Smart Grid, vol.1, no.3, pp. 347-355, 2010.

[14] H. M Dubey., M.Pandit, B.K Panigrahi, "Hybrid flower pollination algorithm with time-varying fuzzy selection mechanism for wind integrated multi-objective dynamic economic dispatch",Renewable Energy, 83,188-202 (2015).

[15] S. H. Karaki, R. B. Chedid, R. Ramadan, "Probabilistic Performance Assessment of Autonomous Solar-Wind Energy Conversion Systems”, IEEE Transactions on Energy Conversion, Vol. 14, No. 3, September 1999. pp. 766-772

[16] H. Bilil, G. Aniba, M. Maaroufi, "Probabilistic Economic Emission Dispatch Optimization of Multi-Sources Power System", Energy Procedia 50 (2014) 789 - 796.

[17] M. Fadaee, M.A.M. Radzi, "Multi-objective Optimization of a stand-alone hybrid renewable energy system by using evolutionary algorithms: A review", Renewable and Sustainable Energy Reviews 16 (2012) 3364-3369.

[18] H.Salimi, "Stochastic fractal search: A powerful metaheuristic algorithm", Knowledge based Systems 75,(2015) 1-18.

[19] J Kiefer, "Sequential minimax search for a maximum", in Proceedings of the American Mathematical Society 4 (3), 1953, pp. 502-506.

[20] M.K. Deshmukh, S.S. Deshmukh, “ Modelling of hybrid renewable energy systems", Renewable and Sustainable Energy Reviews 12 (2008) 235-249

[21] Solar Radiation Hand Book (2008), A joint Project of Solar Energy Centre, MNRE Indian Metrological Department

[22] K. Deb, "Multi objective optimization using evolutionary algorithms", Jhon Wiley \& Sons, 2001.

[23] C.L Hwang, K. Yoon, "Multiple attribute decision making: Method and applications", Spinger-Verlag,New York, NY, 1981.

[24] M. Behzadian., S.K.Otaghsara., M.Yazdani, J. Ignatius, "A state of art survey of TOPSIS applications", Expert system with application.39,13051-69 (2012)

[25] A. Layeb, S. R. Boussalia, "A Novel Quantum Inspired Cuckoo Search Algorithm for Bin Packing Problem", I.J. Information Technology and Computer Science, 4(5), 5867, 2012.

[26] M. Orouskhani,Y. Orouskhani,“A Novel Cat Swarm Optimization Algorithm for Unconstrained Optimization Problems", I.J. Information Technology and Computer Science, 5(11), 32-41, 2013.

[27] D.N. Le, "A New Ant Colony Optimization Algorithm Applied to Optimizing Centralized Wireless Access Network" I.J. Information Technology and Computer Science,6(4), 30-36,2014.

\section{APPENDIX-A}

$\beta=-4.7 \mathrm{e}-3, \eta_{r}=0.105, \eta_{2}=0.9, T_{r e f}=25^{\circ} \mathrm{C}, P_{f}=0.9$, $\mathrm{A}=90363.04 \mathrm{~m}^{2}$ 


\section{Authors' Profiles}

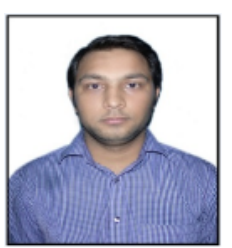

Tushar Tyagi obtained his B.E. degree in Electrical Engineering from JSSATE, Noida (India) in 2012. He is presently doing M.E. in Industrial Systems and Drives (ISD) from M.I.T.S., Gwalior, (India).

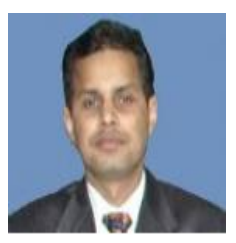

Hari Mohan Dubey obtained his M.E. degree in Electrical Engineering from Madhav Institute of Technology \& Science Gwalior (India) in 2002. He is currently working as Assistant Professor in Department of Electrical Engineering, M.I.T.S., Gwalior, (India). His areas of research are Computational intelligence algorithm and their applications to power system.

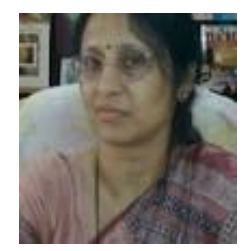

Manjaree Pandit obtained her M. Tech degree in Electrical Engineering from Maulana Azad College of Technology, Bhopal, (India) in 1989 and Ph.D. degree in 2001. She is currently working as Professor in Department of Electrical Engineering, M.I.T.S., Gwalior, (India). Her areas of interest are Power System Security Analysis, Optimization using soft computing/ evolutionary methods, ANN and Fuzzy neural applications to Power System.

How to cite this paper: Tushar Tyagi, Hari Mohan Dubey, Manjaree Pandit,"Multi-Objective Optimal Dispatch Solution of Solar-Wind-Thermal System Using Improved Stochastic Fractal Search Algorithm", International Journal of Information Technology and Computer Science(IJITCS), Vol.8, No.11, pp.61-73, 2016. DOI: 10.5815/ijitcs.2016.11.08 